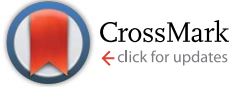

Cite this: RSC Adv., 2017, 7, 13112

Received 31st December 2016 Accepted 19th February 2017

DOI: 10.1039/c6ra28890a

rsc.li/rsc-advances

\section{Preparation of dithiocarbamate polymer brush grafted nanocomposites for rapid and enhanced capture of heavy metal ions $\uparrow$}

\author{
Xin Wang, ${ }^{a}$ Shiyao Jing, ${ }^{a}$ Yingying Liu, ${ }^{a}$ Xiumin Qiu ${ }^{a}$ and Yebang Tan*ab
}

High-density and narrow-distribution dithiocarbamate (DTC) functionalized polymer brush grafted $\mathrm{SiO}_{2}$ nanocomposites (DTC-PGMA@SiO${ }_{2}$ ) were synthesized via surface initiated atom transfer radical polymerization (SI-ATRP) and subsequent DTC functionalization, which could serve as an efficient nanostructured adsorbent material. Systematic characterization was performed to identify the sea anemone like core-brush structure. More importantly, the DTC-PGMA@SiO 2 adsorbent exhibited remarkable performance in capturing heavy metal ions from water. The adsorption behaviour, including the effect of $\mathrm{pH}$, adsorption kinetics, adsorption isotherms, adsorption thermodynamics and adsorption mechanism, was investigated in detail. Interestingly, the adsorbent complexes show different color changes depending upon the species of adsorbed ions, indicating that the DTC-PGMA@SiO ${ }_{2}$ can be potentially used as a sensor for metallic contaminants in water bodies. The regeneration experiments showed that the adsorbent is both cost-effective and sustainable. The high-capacity and rapid adsorption of metallic ions, which are due to the well-defined core-brush structure, large specific surface area and strong binding ability of DTC groups, make this adsorbent material promising in the capture of heavy metal ions from contaminated water.

\section{Introduction}

Water is an essential and significant component of the ecosystem, and plays a vital role in Earth's ecological cycle. ${ }^{1}$ Despite this fact, fresh water systems are directly threatened by heavy metal ions contamination..$^{2-4}$ Heavy metal ions (such as $\mathrm{Pb}^{2+}, \mathrm{Cd}^{2+}, \mathrm{Cr}^{6+}, \mathrm{Hg}^{2+}$, and $\mathrm{Cu}^{2+}$ ) can diffuse into surface and ground waters, posing a critical threat to the ecosystem and public health due to their high toxicity, carcinogenicity, nonbiodegradability and bioaccumulation in the food chain..$^{5-8}$ Common mechanisms regarding the toxicity of heavy metal ions have been reviewed by the World Health Organization (WHO). Some of these include modifying the active conformation of enzymes and proteins, displacing essential metals from biomolecules and disturbing the integrity of biomembranes. ${ }^{\mathbf{9}, 10}$

\footnotetext{
${ }^{a}$ School of Chemistry and Chemical Engineering, Shandong University, Jinan 250100, People's Republic of China. E-mail: ybtan@sdu.edu.cn

${ }^{b}$ The Key Laboratory of Special Functional Aggregated Materials, Ministry of Education, Shandong University, Jinan 250100, People's Republic of China

$\dagger$ Electronic supplementary information (ESI) available: The synthesis method of sacrificial initiator, bare $\mathrm{SiO}_{2}$ and $\mathrm{Br} @ \mathrm{SiO}_{2}$ nanoparticles, the ${ }^{1} \mathrm{H}$ NMR and FTIR spectra of sacrificial initiator and PGMA (Fig. S1-S4); the kinetic plot of SI-ATRP (Fig. S5); the evolution of $M_{\mathrm{n}}$ and PDI versus monomer conversion (Fig. S6); the fitting plots of kinetic and isothermal data (Fig. S7 and S8); the results of reuse experiments (Fig. S9); the elemental analysis results (Table S1), the fitting parameters obtained by using D-R model (Table S2) and the thermodynamic parameters of adsorption process (Table S3). See DOI: 10.1039/c6ra28890a
}

Consequently, this has led to the development of highly efficient technologies for the removal of heavy metal ions from water bodies.

For this purpose, various methods have been developed over the past few years including ion exchange, ${ }^{11}$ chemical precipitation, ${ }^{12}$ membrane filtration, ${ }^{13}$ reverse osmosis, ${ }^{14}$ and adsorption. ${ }^{15}$ By contrast, adsorption is considered to be the most suitable process for capturing metallic ions due to its ease of operation, low cost, high efficiency, and safety. ${ }^{16,17}$ In order to improve the adsorbent performance, organic chelating ligands have been developed based on imidazole, thiol, dithiocarbamate (DTC), and thiourea, or carbonyl groups. ${ }^{18,19}$ It is particularly worth mentioning that the high affinity for metallic ions is a unique characteristic of sulfur containing groups, especially in case of the DTC group. ${ }^{20-22}$ DTC group is well-known to be an soft Lewis base, which could form stable complexes with heavy metal ions (soft Lewis acids) containing partially and fully filled d orbitals through $\pi$-coordinated interactions.

A large number of adsorbent materials have been designed and studied as heavy metal capturing agents. Some of these include biomass materials, ${ }^{23}$ activated carbon, ${ }^{24}$ nanoparticles, ${ }^{25-27}$ polymer resins,${ }^{28}$ and hydrogels. ${ }^{29}$ Compared with other adsorbent materials, nanostructured adsorbent materials exhibit unique properties due to their abundant surface adsorption sites provided by higher specific surface area. ${ }^{\mathbf{3 0 , 3 1}}$ However, the drawbacks of traditional nano-sized adsorbent materials are also obvious. Some of these drawbacks include 
their natural tendency to agglomerate and the limited monolayer adsorption sites attached to the surface..$^{32}$ For this reason, the development of a surface modification to achieve improved and optimized adsorption sites is crucial to the advancement of this field.

Surface functionalization using polymer brush can provide a homogeneous and well-defined interface between nanocomposites and has garnered much attention due to its wide range of applications. ${ }^{33-35}$ Additionally, polymers have been used to effectively reduce the agglomeration of nano-sized materials. ${ }^{36}$ Being inspired by the structure of sea anemone, which is particularly efficient in capturing plankton, the authors of current study have designed a novel nanostructured adsorbent having a core-brush structure similar to sea anemones. Surface-initiated polymerization (SIP) is a facile means of creating high-density polymer brushes on substrates. More importantly, high-density and well-defined polymer brushes having narrow molecular distribution can be precisely fabricated on the matrix surface by using versatile surface-initiated atom transfer radical polymerization (SI-ATRP)..$^{37-40}$

Poly(glycidyl methacrylate) (PGMA), a very valuable polymer, containing active epoxy group that can undergo ring opening reactions with functional ligands. Therefore, the graft of PGMA brush as reactive anchor is of particular interest. Accordingly, adsorptive groups can be introduced to construct efficient adsorptive polymer brush. Surface modification of the adsorptive polymer brushes can not only offer abundant and spatiallyorganized adsorption sites (just like the tentacles of sea anemones), but can also improve their performance for capturing heavy metal ions. Some previous studies have reported such a modification in the field of adsorption. ${ }^{41-43}$ However, few work focused on the fabrication of efficient nanostructured adsorbent materials through SI-ATRP for capturing heavy metal ions.

In this work, a new strategy to design nano-sized heavy metal adsorbent material with core-brush structure is explored by combining SI-ATRP and DTC functionalization. The low-cost bare $\mathrm{SiO}_{2}$ nanoparticles were initially anchored by ATRP initiator, which was further used for grafting PGMA brushes. Subsequently, the DTC groups were introduced to the polymer brushes through ring-opening reaction and DTC functionalization (see Scheme 1). The resultant nanostructured DTC-

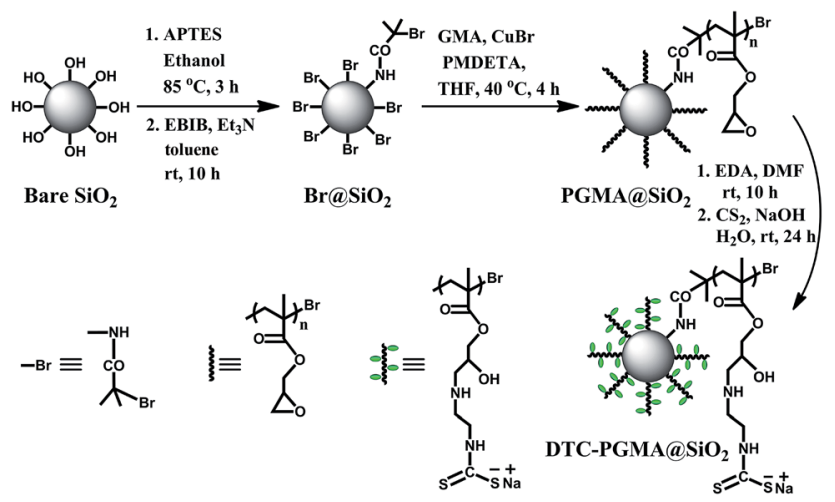

Scheme 1 The synthetic route of nanostructured DTC-PGMA@SiO adsorbent material via SI-ATRP and DTC functionalization.
PGMA@SiO ${ }_{2}$ adsorbent was characterized by various techniques. Moreover, the reported material was finally applied for efficient removal of $\mathrm{Cu}^{2+}, \mathrm{Pb}^{2+}$ and $\mathrm{Cd}^{2+}$ from an aqueous environment. Adsorption behaviours, such as the effect of $\mathrm{pH}$, adsorption kinetics, adsorption isotherms, adsorption thermodynamics and adsorption mechanism were systematically investigated. The regeneration experiments were also conducted to explore the reusability of the studied adsorbent.

\section{Experimental}

\section{Materials and characterization}

Chemicals including 3-triethoxysilylpropylamine (APTES), ethylene diamine tetraacetic acid (EDTA), anisole, $\mathrm{N}, \mathrm{N}$ dimethylformamide (DMF), triethylamine $\left(\mathrm{Et}_{3} \mathrm{~N}\right)$, 2-bromoisobutyryl bromide (BiBB), glycidyl methacrylate (GMA), pentamethyldiethylenetriamine (PMDETA), carbon disulfide $\left(\mathrm{CS}_{2}\right)$, ethylenediamine (EDA) used are all of analytical grade (J\&K Scientific Ltd., Beijing, China). The model sacrificial initiator 2-bromo-2-methyl- $N$-propylpropanamide (BMPA) was self-prepared (see ESI $\dagger$ ). Bare $\mathrm{SiO}_{2}$ nanoparticles and initiator immobilized $\mathrm{SiO}_{2}$ nanoparticles were prepared according to previous reports (see ESI $\dagger$ ). ${ }^{44} \mathrm{CuBr}$ was successively washed with acetic acid and methanol before use. All of the aqueous solutions were prepared using ultrapure water $\left(18.25 \mathrm{M} \Omega \mathrm{cm}\right.$ at $\left.25^{\circ} \mathrm{C}\right)$.

The chemical structures of PGMA brush and synthesized materials were determined by ${ }^{1} \mathrm{H}$ NMR (Bruker AVANCE $300 \mathrm{MHz}$ NMR spectrometer) and FT-IR spectra (Bruker Tensor 27 spectrometer). GPC measurements were performed on a Waters 515 GPC system, which used THF as the eluent (flow rate $1 \mathrm{~mL} \mathrm{~min}^{-1}$ ). TGA was measured by a Netzsch STA 449 instrument from $40{ }^{\circ} \mathrm{C}$ up to $800{ }^{\circ} \mathrm{C}$. The morphology observations of materials were observed with a Hitachi S4800 scanning electron microscope (SEM) and a JEM 1011 transmission electron microscope (TEM). Water contact angle measurements were performed using a Kruss DSA10 optical contact angle system. Elemental analysis of C, H, N and $\mathrm{S}$ was carried out by using an Elementar Vario Cube EL analyser. XPS spectra were acquired by using a Perkin Elmer PHI5300 spectrometer. Zeta potential measurements of adsorbent suspensions $\left(0.2 \mathrm{~g}\right.$ DTC-PGMA@SiO ${ }_{2}$ in $50 \mathrm{~mL}$ of $0.1 \mathrm{~mol} \mathrm{~L}^{-1}$ $\mathrm{NaCl}$ solution) were carried out by a Malvern Zetasizer Nano ZS90 system. The concentrations of metal ions in the solution were determined by inductively coupled plasma-atomic emission spectrometer (ICP-AES, Thermo Optima 7000DV).

\section{Growth of PGMA brushes on $\mathrm{Br} @ S i O_{2}$ nanoparticles}

The surface of prepared $\mathrm{Br}_{0} \mathrm{SiO}_{2}$ nanoparticles can provide abundant initiators for triggering the graft of PGMA brushes through SI-ATRP, during which CuBr/PMDETA (in 1:1 molar ratio, respectively) was used as the catalyst. $4 \mathrm{~g} \mathrm{Br@SiO} 2$, GMA (20 mL; $146.32 \mathrm{mmol})$, BMPA (101.5 mg; $0.487 \mathrm{mmol})$ and PMDETA (100 $\mu \mathrm{L} ; 0.487 \mathrm{mmol})$ were dissolved in $30 \mathrm{~mL}$ anisole. The solution was processed by several freeze-pump-thaw cycles to remove oxygen. $\mathrm{CuBr}(70 \mathrm{mg} ; 0.487 \mathrm{mmol})$ was ultrasonically dispersed in the reaction flask under $\mathrm{N}_{2}$ atmosphere. The 
system was initiated at $40{ }^{\circ} \mathrm{C}$, and the polymerization was stopped after $5 \mathrm{~h}$ by opening the flask. The PGMA brushes grafted $\mathrm{SiO}_{2}$ nanocomposites (PGMA@SiO ${ }_{2}$ ) were purified by THF washing, EDTA (0.05 mol L ${ }^{-1}$ solution) washing, acetone washing and vacuum drying. The free PGMA brushes were precipitated in acetone and were purified through a column of neutral alumina using THF as eluent.

\section{DTC functionalization of PGMA@SiO ${ }_{2}$ nanocomposites}

4 g PGMA@SiO ${ }_{2}$ were dispersed and stirred in $50 \mathrm{~mL} 4 \mathrm{~mol} \mathrm{~L}^{-1}$ EDA/DMF solution for $10 \mathrm{~h}$ at room temperature. The generated amino functionalized PGMA@SiO ${ }_{2}\left(\mathrm{NH}_{2} \text {-PGMA@SiO }\right)_{2}$ nanocomposites were washed thoroughly with acetone and then, were dried under vacuum. $4 \mathrm{~g}$ of prepared $\mathrm{NH}_{2}$-PGMA@SiO ${ }_{2}$ were dispersed in $40 \mathrm{~mL}$ of $2 \mathrm{~mol} \mathrm{~L}^{-1} \mathrm{NaOH}$ aqueous solution. After the addition of $2 \mathrm{~mL} \mathrm{CS}_{2}$, the mixture was stirred at room temperature for $24 \mathrm{~h}$. The target DTC-functionalized PGMA@SiO ${ }_{2}$ (DTC-PGMA@SiO ${ }_{2}$ ) adsorbent nanocomposites were thoroughly and successively washed with water and acetone, and then, were dried under vacuum.

\section{Metallic ions adsorption tests}

All adsorption experiments were performed in batch mode and using a constant temperature incubator shaker (Julabo SW-22) at $150 \mathrm{rpm}$. The effect of $\mathrm{pH}$ (within the range of 1.0-7.0) was investigated in NaAc-HAc buffer solutions having an initial metal ion concentration of $800 \mathrm{mg} \mathrm{L}^{-1}$. The temperature was kept constant at $25{ }^{\circ} \mathrm{C}$ during each 150 minute long adsorption experiment. For kinetic studies, the experiments were carried out at $\mathrm{pH}=5.0$ with different adsorption time intervals (from 3 to $150 \mathrm{~min}$ ) at $25{ }^{\circ} \mathrm{C}$, where the initial concentration of the investigated metallic ion was $800 \mathrm{mg} \mathrm{L}^{-1}$. The adsorption isotherms were investigated at $\mathrm{pH}=5.0$ by varying the initial concentration of heavy metal ions within the range of 200$2000 \mathrm{mg} \mathrm{L}^{-1}$. Furthermore, all isothermal experiments were conducted at three different temperatures (298 K, $308 \mathrm{~K}$ and 318 $\mathrm{K})$ to investigate the adsorption thermodynamic parameters. The adsorption capacity $\left(Q_{\mathrm{e}} ; \mathrm{mmol} \mathrm{g}^{-1}\right)$ and removal efficiency $(R ; \%)$ were calculated using eqn (1) and (2), respectively.

$$
\begin{gathered}
Q_{\mathrm{e}}=V \times\left(C_{0}-C_{\mathrm{e}}\right) / m \\
R=\left(C_{0}-C_{\mathrm{e}}\right) / C_{0} \times 100 \%
\end{gathered}
$$

where $C_{0}$ and $C_{\mathrm{e}}$ represent the initial and equilibrium concentrations of the metallic ions $\left(\mathrm{mmol} \mathrm{L}^{-1}\right)$, respectively; $V$ is the volume of the solution $(20 \mathrm{~mL})$, and $m$ is the mass of adsorbent dosage (20 mg).

\section{Regeneration of DTC-PGMA@SiO ${ }_{2}$ adsorbent}

The adsorbent loaded with heavy metal ions was immersed in $0.2 \mathrm{~mol} \mathrm{~L}^{-1} \mathrm{HNO}_{3}$ solution for $2 \mathrm{~h}$. Next, the adsorbent was successively washed with $0.1 \mathrm{~mol} \mathrm{~L}^{-1}$ EDTA solution, deionized water and acetone. After the centrifugal separation at $11000 \mathrm{rpm}$ for $5 \mathrm{~min}$, the regenerated DTC-PGMA@SiO ${ }_{2}$ nanocomposite was dried under vacuum. The adsorption performance of regenerated
DTC-PGMA@SiO ${ }_{2}$ nanocomposite was evaluated in heavy metal ion solution having an initial concentration of $200 \mathrm{mg} \mathrm{L}^{-1}$ (the adsorption was performed as above-mentioned isothermal adsorption experiment at $25^{\circ} \mathrm{C}, \mathrm{pH}=5.0$ ).

\section{Results and discussion}

\section{FTIR analysis}

Each step in the preparation of DTC-PGMA@SiO ${ }_{2}$ adsorbent was monitored by FTIR spectra (see Fig. 1). The strong adsorption band at $1103 \mathrm{~cm}^{-1}$ was assigned to $\mathrm{Si}-\mathrm{O}-\mathrm{Si}$ stretching vibration of $\mathrm{SiO}_{2}$ substrate. For $\mathrm{Br} @ \mathrm{SiO}_{2}$, the appearance of adsorption bands at $1652 \mathrm{~cm}^{-1}$ and $1553 \mathrm{~cm}^{-1}$ represented the amide condensation reaction between $\mathrm{NH}_{2} @ \mathrm{SiO}_{2}$ and $\mathrm{BiBB}$. Moreover, the appearance of weak $\mathrm{C}-\mathrm{Br}$ band at $550 \mathrm{~cm}^{-1}$ also demonstrated the $\mathrm{BiBB}$ immobilization on $\mathrm{SiO}_{2}$. Compared with Br@SiO ${ }_{2}$, the PGMA@SiO ${ }_{2}$ showed strong adsorption peaks at 2998 and $2988 \mathrm{~cm}^{-1}$, which were attributed to aliphatic $\mathrm{C}-\mathrm{H}$ stretching vibration of PGMA brushes. In addition, the characteristic signals for GMA at 910 (epoxy group) and $1731 \mathrm{~cm}^{-1}$ (carbonyl stretching vibration of the ester group) were observed. ${ }^{45}$ For $\mathrm{NH}_{2}$-PGMA@SiO ${ }_{2}$, both the disappearance of characteristic peak for epoxy group and the appearance of adsorption bands at 3368,3286 and $1475 \mathrm{~cm}^{-1}$ (N-H stretching vibration of primary amino group and $\mathrm{C}-\mathrm{N}$ stretching vibration) represented the introduction of amino groups via an exhaustive ring-opening reaction between PGMA and EDA. The spectrum of DTCPGMA@SiO ${ }_{2}$ showed remarkable characteristic signals for DTC group at 1490 ( $\mathrm{N}-\mathrm{CS}_{2}$ vibration), 985 (C-S vibration) and 1160 $\mathrm{cm}^{-1}\left(\mathrm{C}=\mathrm{S}\right.$ vibration), ${ }^{22}$ indicating that the DTC groups have been successfully introduced in the polymer brushes.

\section{XPS determination and elemental analysis of nanocomposites}

The XPS spectra of $\mathrm{NH}_{2} @ \mathrm{SiO}_{2}, \mathrm{Br} @ \mathrm{SiO}_{2}, \mathrm{PGMA} @ \mathrm{SiO}_{2}$ and DTCPGMA@SiO ${ }_{2}$ have been shown in Fig. 2. The peaks of Si 2p, Si 2s, C 1s, $\mathrm{N} 1 \mathrm{~s}$ and $\mathrm{O}$ 1s were identified in the $\mathrm{NH}_{2} @ \mathrm{SiO}_{2}$ spectrum. The survey spectrum of $\mathrm{Br} @ \mathrm{SiO}_{2}$ confirms the presence of $\mathrm{Br}(\mathrm{Br} 3 \mathrm{~d}$

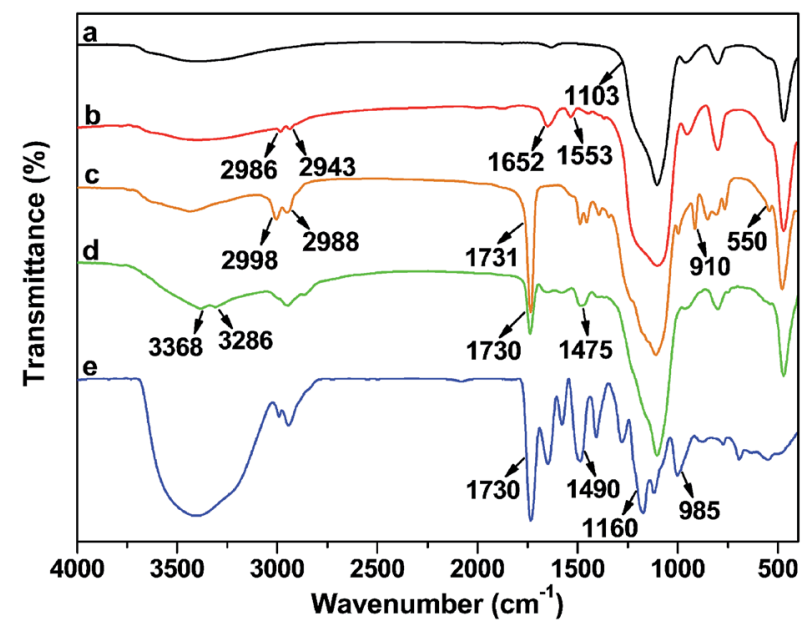

Fig. 1 FTIR spectra of bare $\mathrm{SiO}_{2}(\mathrm{a}), \mathrm{BraSiO}_{2}$ (b), $\mathrm{PGMA@SiO}$ (c), $\mathrm{NH}_{2}-$ PGMA@SiO 2 (d) and DTC-PGMACSiO 2 (e) samples. 


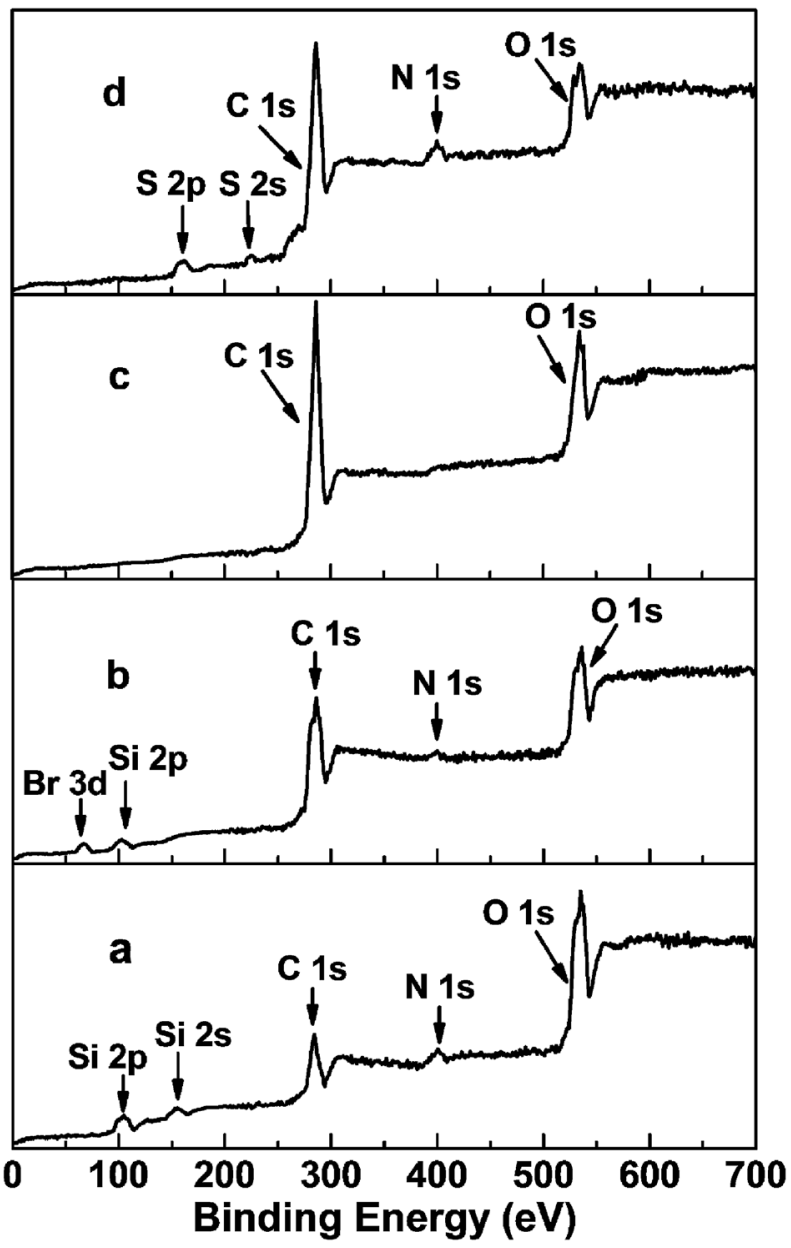

Fig. 2 XPS survey spectra of $\mathrm{NH}_{2} \mathrm{aSiO}_{2}$ (a), $\mathrm{Br}\left(\mathrm{aSiO}_{2}\right.$ (b), $\mathrm{PGMA@ \textrm {SiO } _ { 2 }}$ (c) and DTC-PGMA@SiO 2 (d) samples.

peak at about $69 \mathrm{eV}) .{ }^{46}$ For PGMA@SiO 2 , the remarkable increase in the intensity of $\mathrm{C} 1 \mathrm{~s}$ and the disappearance of Si 2p, Si 2s and $\mathrm{Br}$ 3d peaks implied that the high-density PGMA brushes were grafted on the surface of $\mathrm{SiO}_{2}$ nanoparticles. The signals of $\mathrm{S} 2 \mathrm{~s}$ and $\mathrm{N} 1 \mathrm{~s}$ in the XPS spectrum of DTC-PGMA@SiO ${ }_{2}$ further confirmed the introduction of DTC groups. The elemental analysis results (in Table S1 $\dagger$ ) showed the content of $\mathrm{C}$ increased significantly due to the grafting of PGMA. The $\mathrm{N}$ content was strongly enhanced by the ring-opening reaction occurring between GMA and EDA. The drastic increase of S content from zero to $32.38 \%$ confirmed the introduction of abundant DTC groups (according to sulphur content, the calculated quantity of DTC group is $6.52 \mathrm{mmol} \mathrm{g}^{-1}$ ).

\section{Molecular structure characterization of PGMA brushes}

The synthesized model sacrificial initiator BMPA has very similar initiating chemical structure with the grafted-initiator (see Fig. S1-S3†). It is widely accepted that the ATRP initiated by the model sacrificial initiator shows almost similar polymerization behaviour as the SI-ATRP performed on a solid support. ${ }^{47-49}$ Therefore, the obtained free polymer brushes were generally used to evaluate the control of SI-ATRP experiments. The chemical structure of PGMA brushes was confirmed by ${ }^{1} \mathrm{H}$

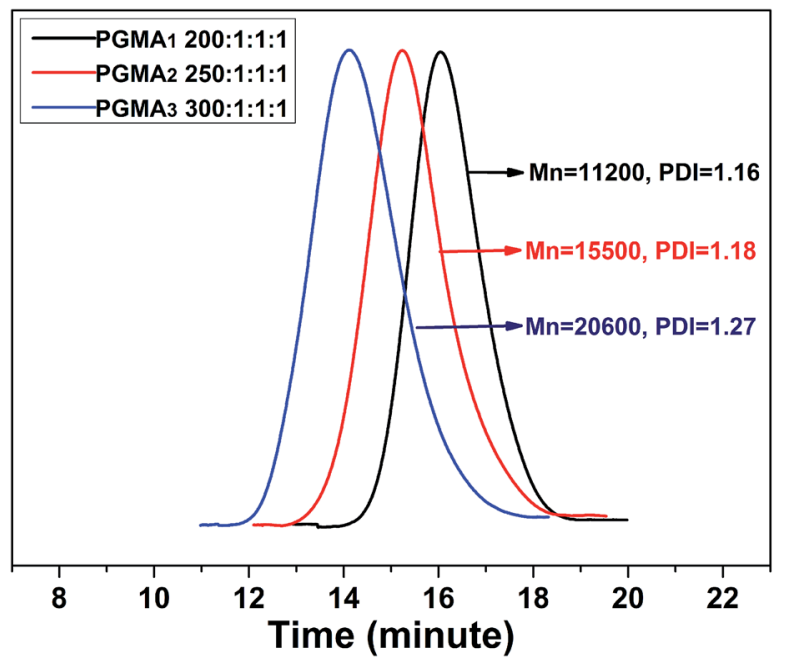

Fig. 3 GPC traces of free PGMA brushes synthesized at different [GMA] : [BMPA] : [CuBr] : [PMDETA] molar ratio.

NMR (see Fig. S4 $\dagger$ ). The GPC traces of free PGMA brushes with various [GMA] : [BMPA] : [CuBr] : [PMDETA] ratios were detected (see Fig. 3), wherein the molecular weight and polydispersity were found to decrease with the increasing initiator content. As shown in Fig. S5, $\uparrow$ the kinetic data of polymerization ([GMA] : [BMPA] : [CuBr] : [PMDETA] is [300] : [1] : [1] : [1]) was found to follow the first-order kinetic model. Fig. S6 $\dagger$ displayed the evolution of $M_{\mathrm{n}}$ and PDI with the monomer conversion. It was found that the $M_{\mathrm{n}}$ of PGMA brush increased linearly with the increase of GMA monomer conversion. Additionally, the narrow PDI values illustrated that the SI-ATRP experiments were well-controlled, and therefore well-defined PGMA brushes were expected to be fabricated on the substrate surface. Ultimately, $\mathrm{PGMA}_{3}$ brushes having the highest molecular weight were selected to perform the present research.

\section{TGA measurements of nanocomposites}

TGA is one of the most appropriate methods to evaluate the thermal stability and graft ratios of the materials. ${ }^{50}$ As shown in Fig. 4, the weight loss increased stage-by-stage from bare $\mathrm{SiO}_{2}$ substrate to DTC-PGMA@SiO ${ }_{2}$. A significant weight loss in PGMA@SiO ${ }_{2}$ (ca. 62.4\%) was observed after $240{ }^{\circ} \mathrm{C}$, which demonstrated a high-density grafting of PGMA brushes. Both $\mathrm{NH}_{2}$-PGMA@SiO ${ }_{2}$ and DTC-PGMA@SiO ${ }_{2}$ displayed another thermal decomposition at around $320{ }^{\circ} \mathrm{C}$, which implied that a new chemical structure has emerged following the ringopening reaction. The final weight loss ratios of $\mathrm{NH}_{2}$ PGMA@SiO ${ }_{2}$ and DTC-PGMA@SiO ${ }_{2}$ were found to be $76.2 \%$ and $84.2 \%$, respectively. These results indicated complete evolution of ring opening reaction and DTC functionalization.

\section{Morphology observations of nanocomposites}

TEM micrographs of bare $\mathrm{SiO}_{2}, \mathrm{PGMA@SiO} 2$ and DTCPGMA@SiO ${ }_{2}$ are displayed in Fig. 5a-c respectively. Compared with the bare $\mathrm{SiO}_{2}$, the PGMA@SiO 2 clearly showed the grafted polymer brushes, while the agglomeration of nanocomposites 


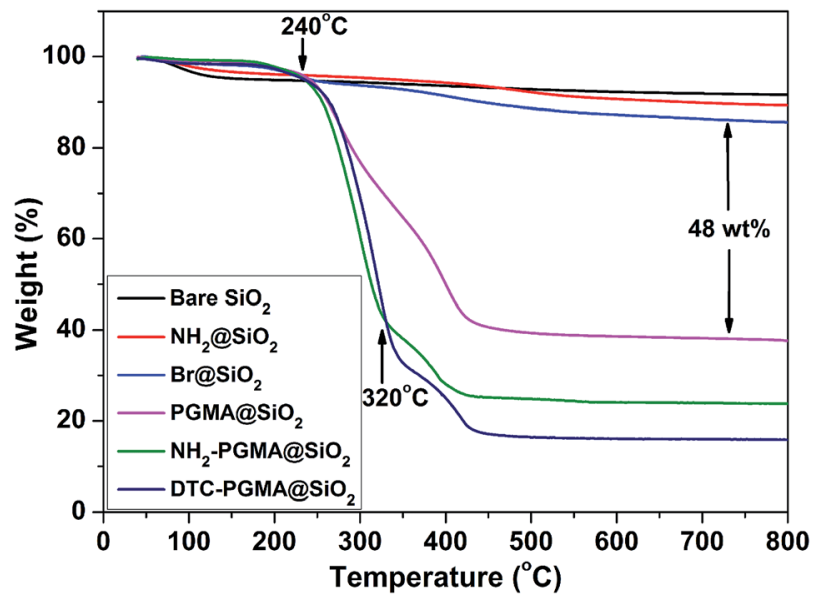

Fig. 4 TGA curves of synthesized nanocomposites.

turned obvious. This is due to the reason that water is a poor solvent for PGMA. So, the brushes curl to form links between PGMA@SiO ${ }_{2}$ nanocomposites in water, which exacerbate the agglomeration. After the DTC modification, all of the nanocomposites in water seemed to be finely dispersed and appeared to be much bigger than before (the size of DTC-PGMA@SiO ${ }_{2}$ is about $200 \mathrm{~nm}$ in water). This is due to the reason that the negatively charged DTC-modified polymer brushes exhibit super hydrophilicity. Besides, these have electrostatic repulsions in between them. Accordingly, these brushes become stretched in water and hence, the dispersibility of nanocomposites is remarkably improved. In this form, the DTCPGMA@SiO ${ }_{2}$ adsorbent exhibits unique advantages to capture heavy metal ions from aqueous environments.

\section{Measurement of water contact angle of nanocomposites}

Materials generally show significant difference in wettability following surface modification. ${ }^{51,52}$ The wettability of sample disks including $\mathrm{SiO}_{2}, \quad \mathrm{PGMA} @ \mathrm{SiO}_{2}$ and DTC-PGMA@SiO (Fig. 5d-f, respectively) was assessed. For bare $\mathrm{SiO}_{2}$, the $\mathrm{Si}-\mathrm{OH}$ groups make the surface hydrophilic (water contact angle of around $28^{\circ}$ ). However, the majority of $\mathrm{Si}-\mathrm{OH}$ groups are consumed during the condensation reaction involving $\mathrm{Si}-$ $\mathrm{OC}_{2} \mathrm{H}_{5}$ groups of APTES. Additionally, the grafting of highdensity hydrophobic PGMA brushes leads to a much more

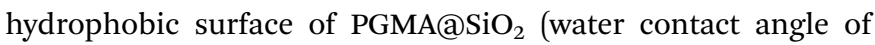
around $87^{\circ}$ ). However, the water drops were found to readily wet the surface of DTC-PGMA@SiO ${ }_{2}$ disk. A transition to a super hydrophilic surface is observed on the DTC-PGMA@SiO ${ }_{2}$ disk as the contact angle decreases to $9^{\circ}$. Thus, the changes in wettability and TEM observations provide useful complementary information, testifying that the design of nanostructured DTCPGMA@SiO ${ }_{2}$ adsorbent occurred as expected.

\section{Effect of $\mathrm{pH}$ on adsorption}

The surface charge of the adsorbent, ionization of functional groups and speciation of heavy metal ions are strongly affected by the $\mathrm{pH}$ of environment. Consequently, the $\mathrm{pH}$ effect on the removal of heavy metal ions using DTC-PGMA@SiO ${ }_{2}$ was investigated. As shown in Fig. 6a, poor uptake of metallic ions was observed in strongly acidic environment $(\mathrm{pH}<3.0)$, while it increased remarkably for a higher $\mathrm{pH}$ value. The maximum uptake of $\mathrm{Cu}^{2+}, \mathrm{Pb}^{2+}$ and $\mathrm{Cd}^{2+}\left(3.45,1.97\right.$ and $1.56 \mathrm{mmol} \mathrm{g}^{-1}$, respectively) was observed at a $\mathrm{pH}$ of 5.0. To elaborate this phenomenon, the $\mathrm{pH}$ point of zero charge $\left(\mathrm{pH}_{\mathrm{PZC}}\right)$ of the nanostructured DTC-PGMA@SiO ${ }_{2}$ adsorbent was measured via zeta
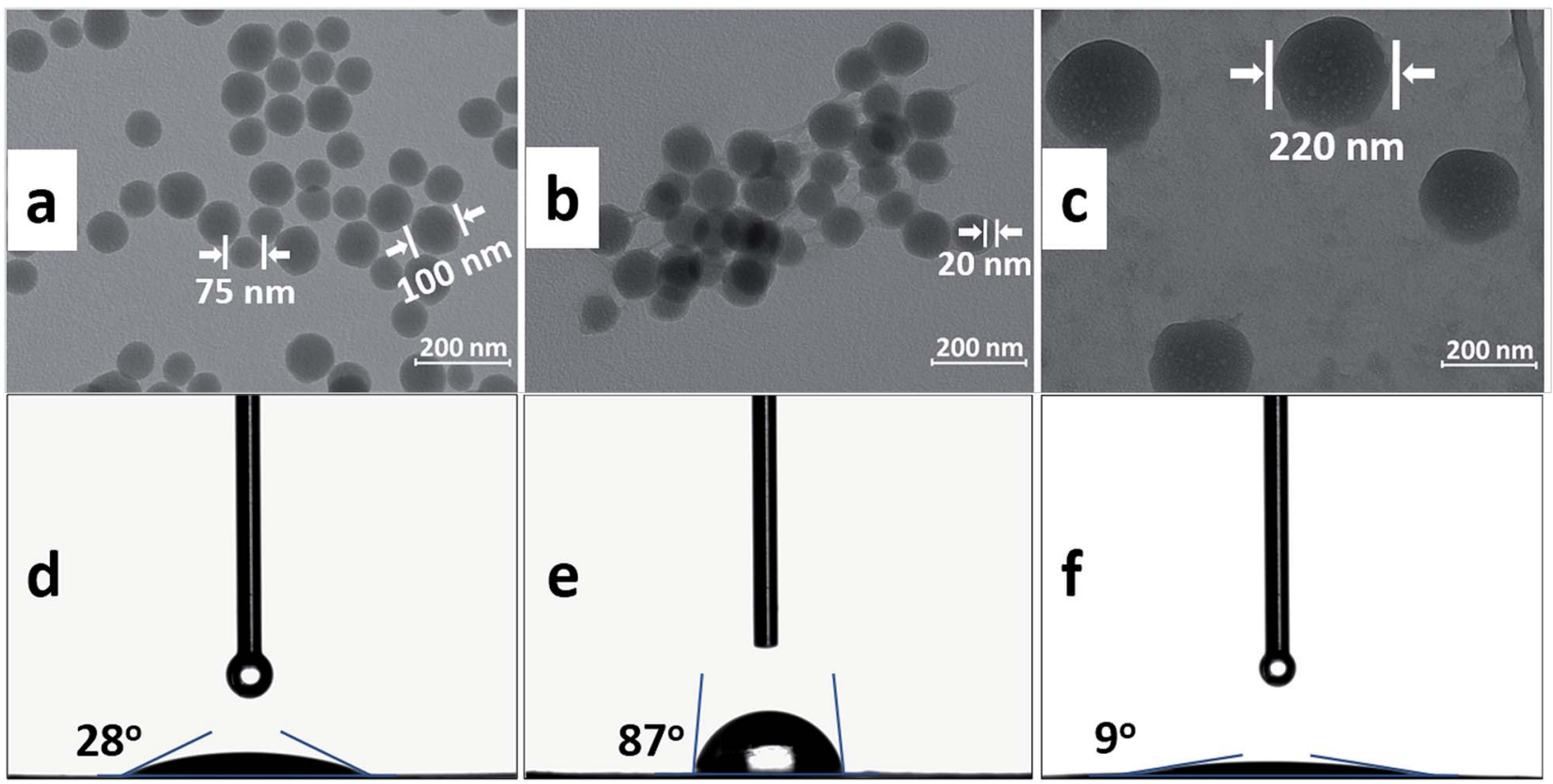

Fig. 5 TEM images of bare $\mathrm{SiO}_{2}$ nanoparticles (a), $\mathrm{PGMACSiO}$ (b) and DTC-PGMA@SiO 2 (c) dispersed in water. Water contact angle measurements on bare $\mathrm{SiO}_{2}$ (d), $\mathrm{PGMA} \mathrm{CSiO}_{2}$ (e) and DTC-PGMA@SiO 2 (f) sample disks are shown. 

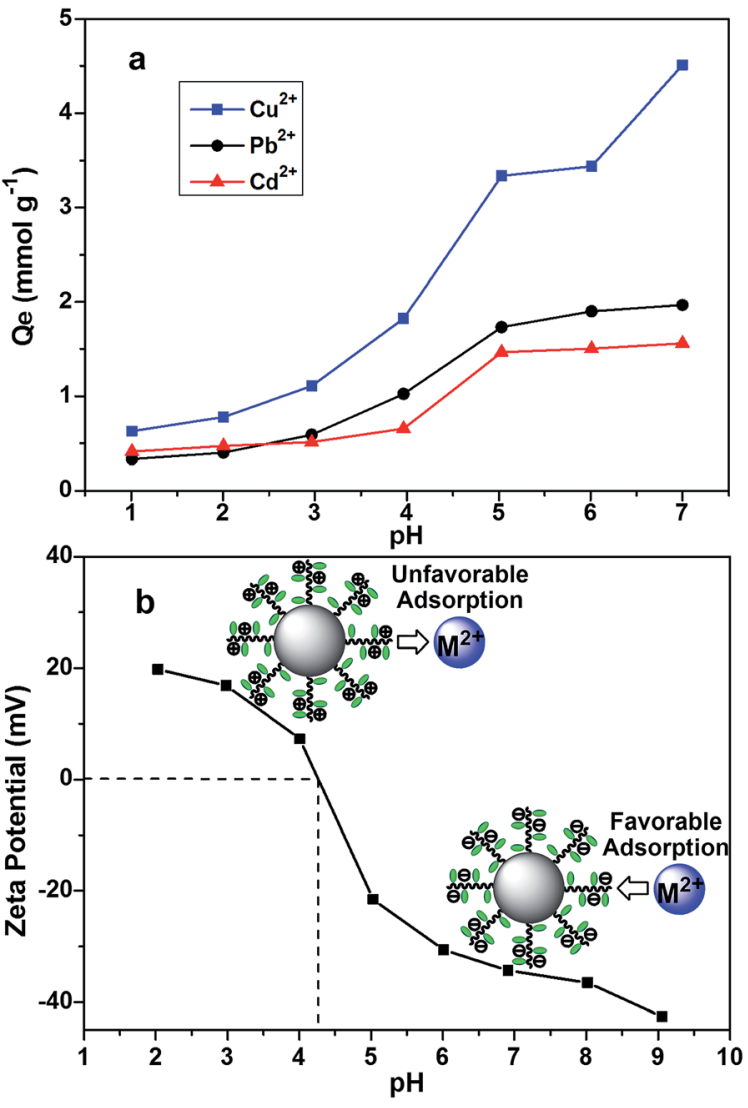

Fig. 6 (a) Adsorption capacity as a function of the $\mathrm{pH}$ for the studied metal ions. (b) Zeta potential of the DTC-PGMA@SiO ${ }_{2}$ suspension as a function of the $\mathrm{pH}$.

potential method (see Fig. $6 \mathrm{~b}$ ). The $\mathrm{pH}_{\mathrm{PZC}}$ was found to be about 4.3. It is well-known that the adsorbent surface is positively charged at $\mathrm{pH}<\mathrm{pH}_{\mathrm{PZC}}$, while it is negatively charged at $\mathrm{pH}>$ $\mathrm{pH}_{\mathrm{PZC}}{ }^{53,54}$ Under low $\mathrm{pH}$ conditions $\left(\mathrm{pH}<\mathrm{pH}_{\mathrm{PZC}}\right)$, the functional groups (amine and DTC groups on the polymer brushes) were protonated, indicating that abundant $\mathrm{H}^{+}$ions would dominantly compete with heavy metal ions for binding these adsorptive sites. Conversely, the removal of metallic ions was facilitated significantly with an increase in the $\mathrm{pH}$ value. However, the generation of precipitates of metallic hydroxides obviously disturbed the accurate evaluation of adsorption capacity at higher $\mathrm{pH}$ values $(\mathrm{pH} \geq 6.0)$. Therefore, $\mathrm{pH}=5.0$ was chosen to perform further experiments to study the adsorption behaviour.

\section{Adsorption kinetics}

In order to investigate the performance of DTC-PGMA@SiO ${ }_{2}$ adsorbent, the adsorption kinetics for metallic ions (including $\mathrm{Cu}^{2+}, \mathrm{Pb}^{2+}$ and $\mathrm{Cd}^{2+}$ ) were examined. As shown in Fig. $7 \mathrm{a}$, the time to reach equilibrium was found to be less than $30 \mathrm{~min}$ for the investigated ions. Such a rapid adsorption is ascribed to the large specific surface area and the strong metal affinity of DTC groups. Remarkably, for $\mathrm{Pb}^{2+}$, the adsorption equilibrium time is only about $15 \mathrm{~min}$. This is due to the smaller ionic radius of hydrated $\mathrm{Pb}^{2+}(4.01 \AA)$ compared to those of $\mathrm{Cu}^{2+}(4.19 \AA)$ and $\mathrm{Cd}^{2+}(4.26 \AA),{ }^{55,56}$ resulting in an easier diffusion of $\mathrm{Pb}^{2+}$ to the
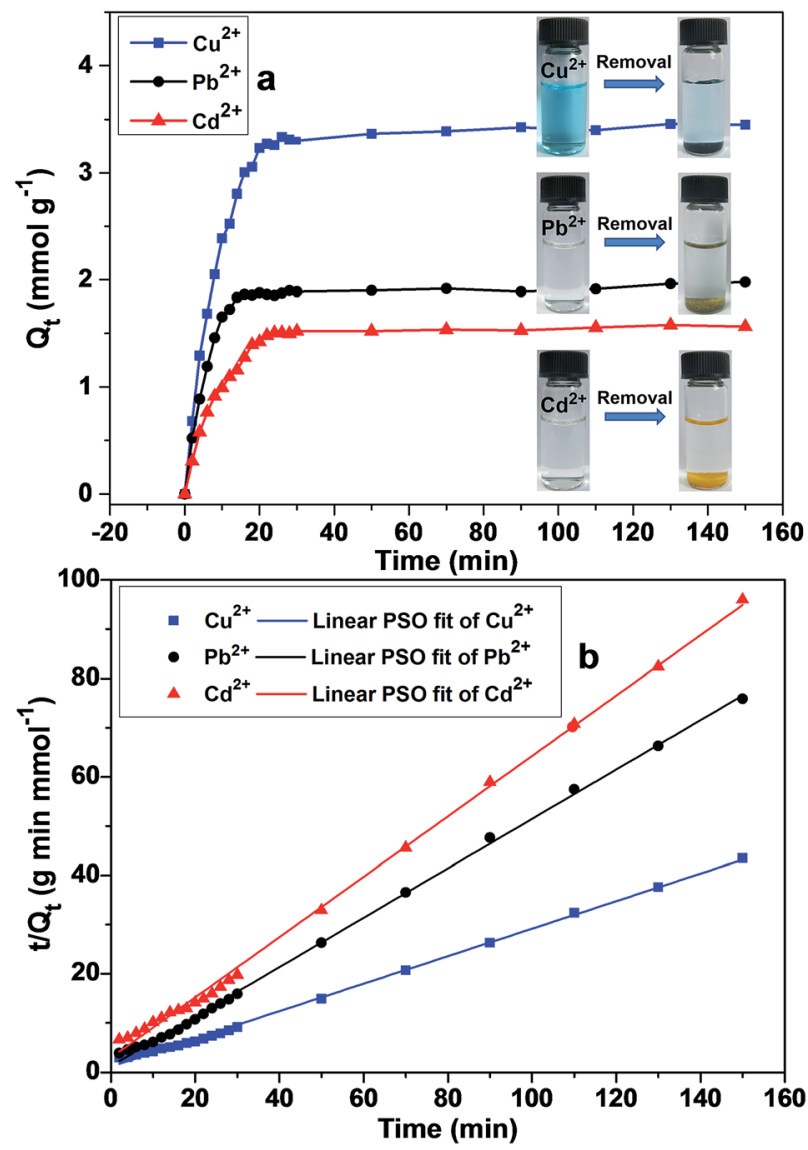

Fig. 7 (a) Adsorption kinetics of metal ions on DTC-PGMA@SiO 2 at 298 K. (b) Linear fitting plots of kinetic data using a pseudo-secondorder model.

adsorption sites. ${ }^{22,57}$ In order to further understand the mechanism of adsorption process, linear pseudo-first-order (PFO) and pseudo-second-order (PSO) models were used to fit the kinetic data. The governing equations for the models are given by eqn (3) and (4), respectively. ${ }^{43,58}$

$$
\begin{gathered}
\ln \left(Q_{\mathrm{e}}-Q_{t}\right)=\ln Q_{\mathrm{e}}-k_{1} t \\
t / Q_{t}=1 /\left(k_{2} Q_{\mathrm{e}}{ }^{2}\right)+t / Q_{\mathrm{e}}
\end{gathered}
$$

where $Q_{\mathrm{e}}$ and $Q_{t}\left(\mathrm{mmol} \mathrm{g}^{-1}\right)$ are the amounts of adsorbed metal ions at equilibrium and at test time $t(\mathrm{~min})$, respectively. In eqn (3) and (4), $k_{1}\left(\mathrm{~min}^{-1}\right)$ and $k_{2}\left(\mathrm{~g} \mathrm{mmol}^{-1} \mathrm{~min}^{-1}\right)$ are the relevant rate constants.

Linear fitting plots were shown in Fig. 7b (fitting plots using PFO model were shown in Fig. S7 $\dagger$ ) and the corresponding fitting parameters were reported in Table 1 . According to $R^{2}$ values, PSO represented the experimental data better than the PFO model. These results demonstrated that the adsorption process of metallic ions onto the DTC-PGMA@SiO ${ }_{2}$ adsorbent could well be explained by the pseudo-second-order kinetic model. This also indicated that the rate-limiting step should be the chemisorption of adsorbate on the adsorbent represented by the valence force through an exchange of electrons between DTC ligands and metallic ions. ${ }^{22,56}$ It is interesting to note that 
Table 1 Kinetic data obtained by PFO and PSO models for the adsorption of heavy metal ions on the nanostructured DTCPGMA@SiO 2 adsorbent at $298 \mathrm{~K}$

\begin{tabular}{lllll}
\hline \multirow{5}{*}{ Model } & Metal ion & $R^{2}$ & $Q_{\mathrm{e}}\left(\mathrm{mmol} \mathrm{g}^{-1}\right)$ & $K_{1}\left(\mathrm{~min}^{-1}\right)$ \\
\cline { 3 - 5 } PFO & $\mathrm{Cu}^{2+}$ & 0.298 & 10.11 & 0.0011 \\
& $\mathrm{~Pb}^{2+}$ & 0.194 & 11.02 & 0.0037 \\
& $\mathrm{Cd}^{2+}$ & 0.314 & 11.51 & 0.0042 \\
\hline
\end{tabular}

\begin{tabular}{lllll}
\hline \multirow{5}{*}{ Model } & Metal ion & $R^{2}$ & $Q_{\mathrm{e}}\left(\mathrm{mmol} \mathrm{g}^{-1}\right)$ & $K_{2}\left(\mathrm{mmol} \mathrm{g}^{-1} \mathrm{~min}^{-1}\right)$ \\
\cline { 3 - 5 } PSO & $\mathrm{Cu}^{2+}$ & 0.998 & 3.57 & 0.167 \\
& $\mathrm{~Pb}^{2+}$ & 0.999 & 1.99 & 0.203 \\
& $\mathrm{Cd}^{2+}$ & 0.998 & 1.60 & 0.131
\end{tabular}

the chelate complexes show different colour changes depending upon the adsorbed ions (see Fig. 7a), which due to the charge transfer between ligand and metal ions..$^{59}$ Consequently, DTCPGMA@SiO ${ }_{2}$ can be used as a potential sensor to identify the contaminating ions in water.

\section{Adsorption isotherms}

The study of adsorption isotherms gives a more profound understanding of the adsorbent's performance. Fig. 8 displayed the adsorption isotherms of $\mathrm{Cu}^{2+}, \mathrm{Pb}^{2+}$ and $\mathrm{Cd}^{2+}$ on the nanostructured DTC-PGMA@SiO ${ }_{2}$ at $298 \mathrm{~K}$. It can be seen that the uptake of heavy metal ions showed a steeper curve at low concentrations, which gradually reached a plateau at higher concentrations. The adsorption of $\mathrm{Cu}^{2+}\left(3.60 \mathrm{mmol} \mathrm{g}^{-1}\right)$ was found to be higher than those of $\mathrm{Pb}^{2+}\left(1.96 \mathrm{mmol} \mathrm{g}^{-1}\right)$ and $\mathrm{Cd}^{2+}$ $\left(1.47 \mathrm{mmol} \mathrm{g}^{-1}\right)$. The Langmuir and Freundlich empirical isotherm models were fitted to the experimental data. The Langmuir isotherm describes the adsorption on a homogeneous surface, assuming equal adsorption sites, a monolayer surface coverage of adsorbate and no interaction between the adsorbed ions..$^{59}$ The Freundlich model depicts an adsorption on a heterogeneous surface, possessing discriminatory adsorption sites and a binding affinity which decreases with the increase in adsorption degree. ${ }^{60}$ The Langmuir and Freundlich isotherms are represented by eqn (5) and (6), respectively.

$$
\begin{gathered}
C_{\mathrm{e}} / Q_{\mathrm{e}}=C_{\mathrm{e}} / Q_{\mathrm{m}}+1 / Q_{\mathrm{m}} K_{\mathrm{L}} \\
\ln Q_{\mathrm{e}}=\ln K_{\mathrm{F}}+1 / n \ln C_{\mathrm{e}}
\end{gathered}
$$

where $Q_{\mathrm{e}}\left(\mathrm{mmol} \mathrm{g}^{-1}\right)$ is the adsorption capacity, $Q_{\mathrm{m}}\left(\mathrm{mmol} \mathrm{g}^{-1}\right)$ is the maximum adsorption capacity, $C_{\mathrm{e}}\left(\mathrm{mmol} \mathrm{L}^{-1}\right)$ is the equilibrium concentration of heavy metal ion in the solution, $K_{\mathrm{F}}$ is a constant reflecting the binding affinity and $K_{\mathrm{L}}$ is the Langmuir adsorption equilibrium constant.

The corresponding results for the fit of Langmuir and Freundlich models have been shown in Fig. 8 and S8, $\dagger$ respectively. Comparing the $R^{2}$ values in Table 2, Langmuir model shows better fit for the experimental data, which demonstrates that the adsorption of metal ions on the DTC-PGMA@SiO ${ }_{2}$ adsorbent is a monolayer, chemisorption onto a homogeneous surface. The Dubinin-Radushkevitch (D-R) eqn (7) was used to further describe the metal ions' adsorption process.

$$
\ln Q_{\mathrm{e}}=\ln Q_{\mathrm{m}}-k \varepsilon^{2}
$$

where $k\left(\mathrm{~mol}^{2} \mathrm{~kJ}^{-2}\right)$ is a constant related to the average adsorption energy $(E)$ and $\varepsilon$ is equal to $\left[R T \ln \left(1+1 / C_{\mathrm{e}}\right)\right]$. Furthermore, the $E$ value can be calculated from the $k$ value using eqn (8).

$$
E=(2 k)^{-1 / 2}
$$

In the present work, $E$ values for the studied metallic ions were found to lie within a range of $18-23 \mathrm{~kJ} \mathrm{~mol}^{-1}$ (see Table S2 $\dagger$ ). This suggests that a strong binding interaction occurs during the adsorption process rather than a simple ion exchange. DTC is well-known to be an anionic dithio ligand, which could form stable complexes with heavy metal ions containing partially and fully filled d orbitals through $\pi$-coordinated interactions. From the ligand field stabilization energy theory, $\mathrm{d}^{9}$ type metal ions ( such as $\mathrm{Cu}^{2+}$ ) have stronger stabilization energy with respect to $\mathrm{d}^{10}$ type ions (such as $\mathrm{Pb}^{2+}$ and $\mathrm{Cd}^{2+}$ ) and therefore, a more significant coordination interaction can be achieved for $\mathrm{Cu}^{2+} .{ }^{61}$ Differences in the adsorption of $\mathrm{Pb}^{2+}$ and $\mathrm{Cd}^{2+}$ mainly rely on their electronegativity, which are 2.33 for $\mathrm{Pb}$ and 1.7 for $\mathrm{Cd}$. The higher electronegativity of $\mathrm{Pb}$ reflects its higher tendency to share electrons with respect to $\mathrm{Cd}$, thus favouring its adsorption on DTC-PGMA@SiO ${ }_{2}$ adsorbent. ${ }^{22}$ Therefore, the capacity of DTC-PGMA@SiO ${ }_{2}$ adsorbent for
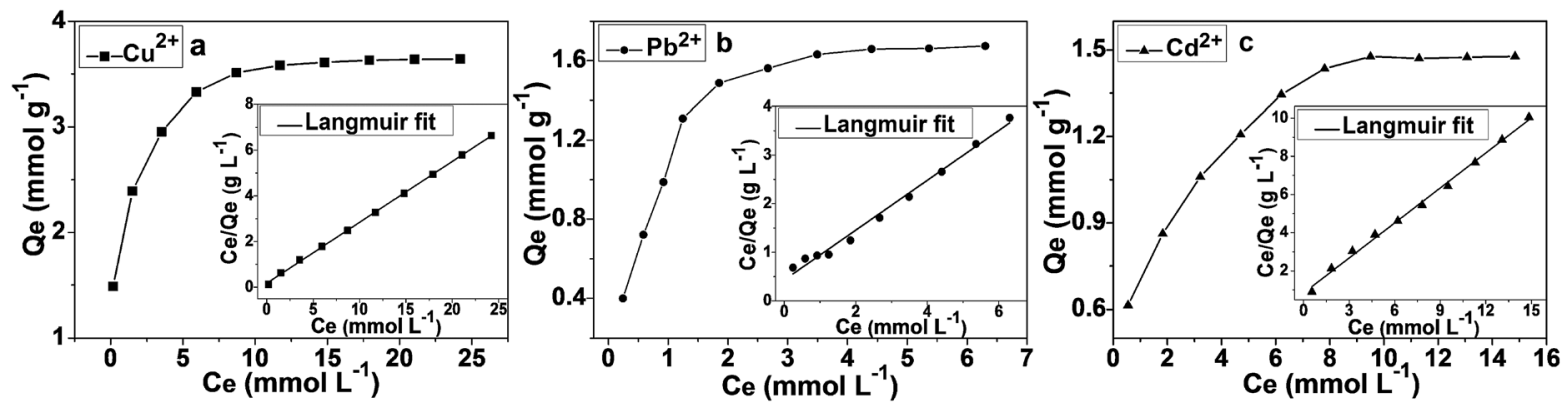

Fig. 8 Adsorption isotherms and relative Langmuir linear fits for the adsorption of $\mathrm{Cu}^{2+}(\mathrm{a}), \mathrm{Pb}^{2+}$ (b) and Cd ${ }^{2+}$ (c) on DTC-PGMA@SiO 2 at $298 \mathrm{~K}$. 
Table 2 Isothermal parameters obtained by using Langmuir and Freundlich models for the adsorption of heavy metal ions on the nanostructured DTC-PGMA@SiO 2 adsorbent at $298 \mathrm{~K}$

\begin{tabular}{lllll}
\hline \multirow{5}{*}{ Model } & Metal ion & $R^{2}$ & $Q_{\mathrm{m}}\left(\mathrm{mmol} \mathrm{g}^{-1}\right)$ & $K_{\mathrm{L}}\left(\mathrm{L} \mathrm{mmol}^{-1}\right)$ \\
\cline { 3 - 5 } Langmuir & $\mathrm{Cu}^{2+}$ & 0.999 & 3.75 & 1.526 \\
& $\mathrm{~Pb}^{2+}$ & 0.990 & 1.94 & 0.991 \\
& $\mathrm{Cd}^{2+}$ & 0.996 & 1.64 & 0.727 \\
\hline \multirow{5}{*}{ Model } & & \multicolumn{2}{l}{ Fitting parameters } \\
\cline { 3 - 5 } Freundlich & $\mathrm{Cu}^{2+}$ & 0.921 & 5.39 & $K_{\mathrm{F}}\left(\mathrm{mmol}^{1-1 / n} \mathrm{~L}^{1 / n} \mathrm{~g}^{-1}\right)$ \\
& $\mathrm{Pb}^{2+}$ & 0.853 & 2.20 & 2.19 \\
& $\mathrm{Cd}^{2+}$ & 0.935 & 3.52 & 0.90 \\
& & & & 0.75 \\
\hline
\end{tabular}

capturing the studied metallic ions can be represented as $\mathrm{Cu}^{2+}>$ $\mathrm{Pb}^{2+}>\mathrm{Cd}^{2+}$. The results showed that the reported DTCPGMA@SiO ${ }_{2}$ adsorbent shows an outstanding adsorption performance including remarkable adsorption capacity and rapid adsorption rate, which due to the sea anemone like corebrush structure, the strong binding affinity between metal ions and DTC ligand and the high specific area. The comparison between DTC-PGMA@SiO ${ }_{2}$ nanocomposite and some other nanomaterials regarding to the adsorption performance of $\mathrm{Cu}^{2+}, \mathrm{Pb}^{2+}$ and $\mathrm{Cd}^{2+}$ from aqueous environment was listed in Table 3 .

\section{Adsorption thermodynamics}

Adsorption thermodynamics were investigated through temperature-dependent isotherms (see Fig. 9a-c). Van't Hoff equation, as given by eqn (9), is used to calculate the adsorption Gibbs free energy $\left(\Delta G ; \mathrm{kJ} \mathrm{mol}^{-1}\right)$, adsorption enthalpy $(\Delta H ; \mathrm{kJ}$ $\left.\mathrm{mol}^{-1}\right)$ and adsorption entropy $\left(\Delta S ; \mathrm{J} \mathrm{mol}^{-1} \mathrm{~K}^{-1}\right)$

$$
\ln K_{\mathrm{c}}=-\Delta H / R T+\Delta S / R
$$

where $K_{\mathrm{c}}$ is the adsorption equilibrium constant obtained from Langmuir isotherms at various temperatures, $R$ is the ideal gas constant (8.314 $\mathrm{J} \mathrm{mol}^{-1} \mathrm{~K}^{-1}$ ), and $T$ is the absolute temperature (K).

The values of $\Delta H$ and $\Delta S$ can be geometrically extracted from the linear fit of $\ln K_{\mathrm{c}}$ versus $1 / T$ (as shown in Fig. 9d). $\Delta G$ can be calculated from $\Delta H$ and $\Delta S$ values by using eqn (10).

$$
\Delta G=\Delta H-T \Delta S
$$

The thermodynamic parameters for the studied metallic ions are tabulated in Table S3. $\dagger$ Since $\Delta G$ values are more negative at higher temperatures, therefore the spontaneous adsorption is favoured by high temperatures. Positive $\Delta H$ values indicate an endothermic adsorption process. ${ }^{67}$ The calculated $\Delta S$ values also demonstrate that the adsorption process is favoured by the entropy.

\section{Adsorption mechanism}

The adsorption mechanism of heavy metal ions using DTCPGMA@SiO ${ }_{2}$ adsorbent is relied on synergistic combination of electrostatic interaction (between metallic ions and functional groups such as amino and DTC groups) and some other stronger chemical interactions. On the basis of hard and soft acids and bases theory, the adsorption may be dominated by the coordination interaction between metal ions and DTC groups. In order to confirm this, FTIR and high-resolution XPS analysis of $\mathrm{Cu}^{2+}$ / DTC-PGMA@SiO ${ }_{2}$ complex were performed. The red-shift and the intensity reduction of characteristic FTIR DTC signals (C-S and $\mathrm{C}=\mathrm{S}$ stretching vibrations) following the adsorption of $\mathrm{Cu}^{2+}$, clearly demonstrated that the coordination interactions between $\mathrm{Cu}^{2+}$ and DTC groups actually occurred (see Fig. 10a). In XPS spectrum of $\mathrm{Cu} 2 \mathrm{p}$ (see Fig. 10b), $\mathrm{Cu} 2 \mathrm{p}_{3 / 2}\left(932.5 \mathrm{eV}\right.$ ) and $\mathrm{Cu} 2 \mathrm{p}_{1 / 2}$ $(952.2 \mathrm{eV})$ peaks were identified, indicating the presence of $\mathrm{Cu}(\mathrm{II}) .{ }^{68}$ The S $2 \mathrm{p}_{3 / 2}(161.9 \mathrm{eV})$ and S $2 \mathrm{p}_{1 / 2}(163.3 \mathrm{eV})$ peak doublet contributed to the unique DTC sulphur signal (see Fig. 10c), which is consistent with the reported DTC-metal ion interaction. ${ }^{68-70}$ Additionally, the highly coloured chelate complex and the discussed adsorption preference could be regarded as other proofs. By comparing the FTIR spectra and S 2p XPS signal of

Table 3 Comparison of the adsorption performance of DTC-PGMA@SiO ${ }_{2}$ nanocomposite and some other nanomaterials

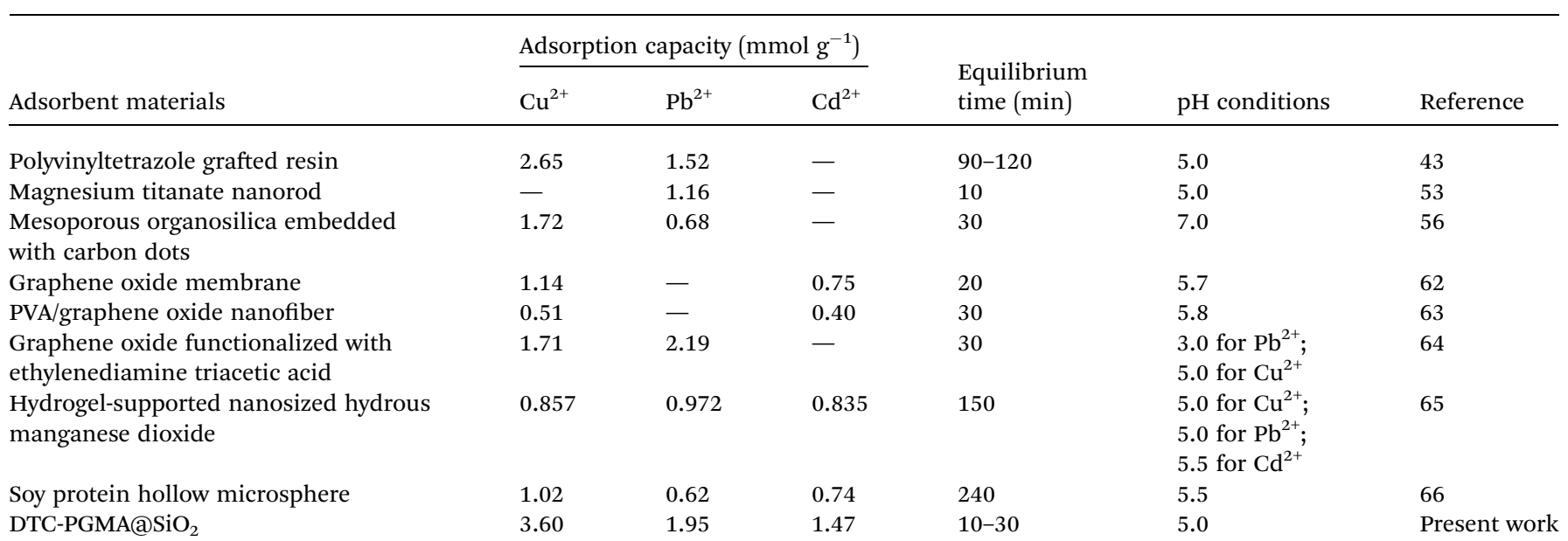



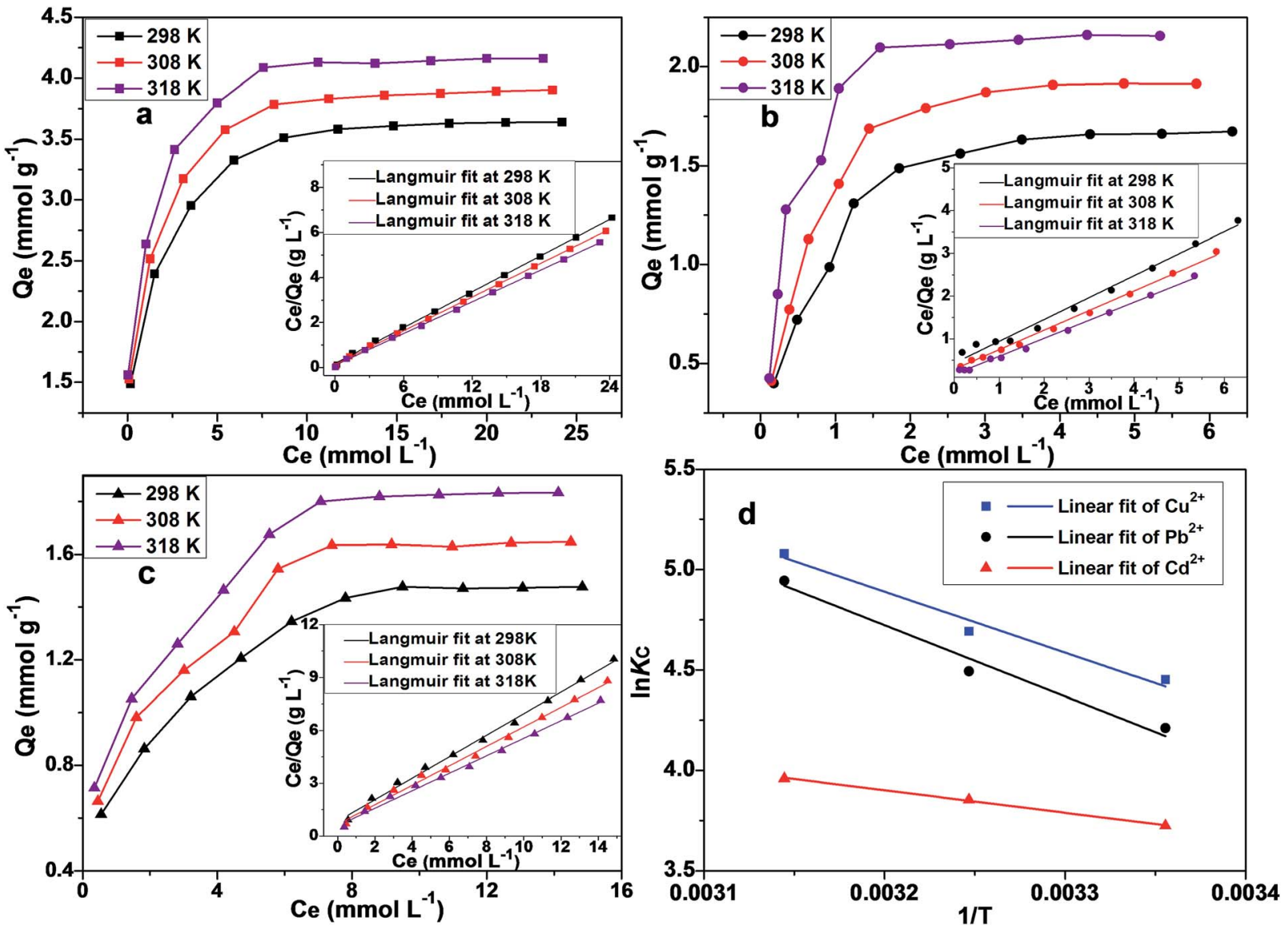

Fig. 9 Adsorption isotherms and Langmuir linear fits for the adsorption of $\mathrm{Cu}^{2+}$ (a), $\mathrm{Pb}^{2+}$ (b) and $\mathrm{Cd}^{2+}$ (c) at $298 \mathrm{~K}, 308 \mathrm{~K}$ and $318 \mathrm{~K}$. (d) The linear fitting plots for $\ln K_{\mathrm{c}}$ versus $1 / T$ according to Van't Hoff equation.
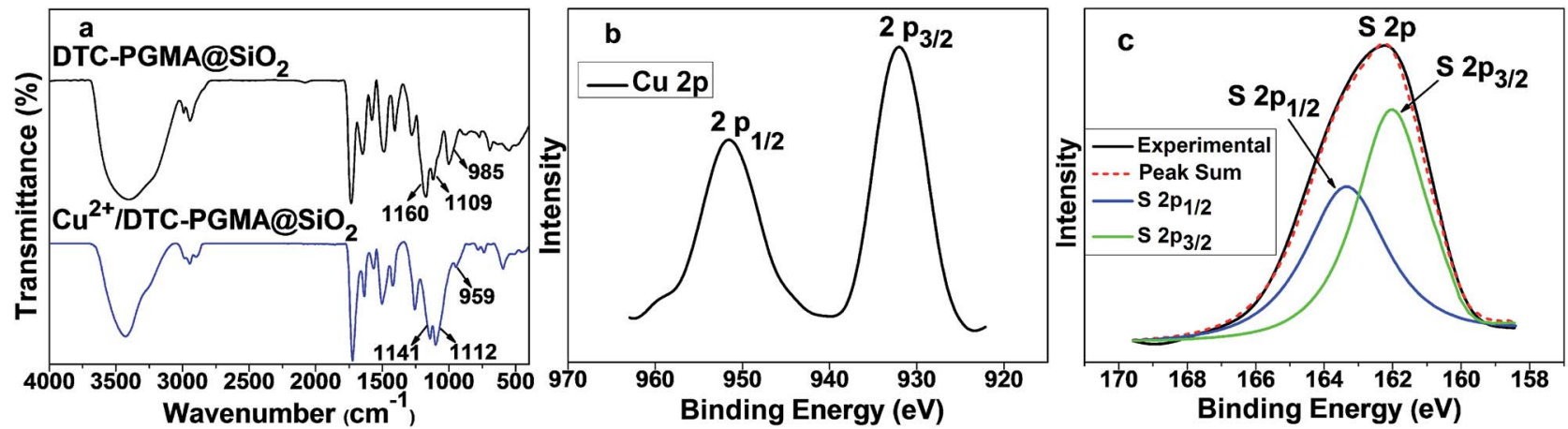

Fig. 10 (a) FTIR spectra of DTC-PGMA@SiO 2 adsorbent and the $\mathrm{Cu}^{2+} / \mathrm{DTC}-\mathrm{PGMA@SiO} 2$ complex. High-resolution XPS data of Cu 2p (b) and S $2 \mathrm{p}$ (c) signals of the $\mathrm{Cu}^{2+} / \mathrm{DTC}-\mathrm{PGMA} \mathrm{aSiO}_{2}$ complex.

$\mathrm{Cu}^{2+} /$ DTC-PGMA@SiO 2 complex, $\mathrm{Pb}^{2+} /$ DTC-PGMA@SiO ${ }_{2}$ complex and $\mathrm{Cd}^{2+} /$ DTC-PGMA@SiO 2 complex, we found no significant differences. Therefore, the adsorption mechanism of the investigated heavy metal ions using DTC-PGMA@SiO ${ }_{2}$ adsorbent can be summarized as a unified principle. To summarize, these results confirmed that the metallic ions can be adsorbed on DTCPGMA@SiO ${ }_{2}$ via electrostatic interaction and coordination interaction with DTC groups.

\section{Regeneration of DTC-PGMA@SiO ${ }_{2}$ adsorbent}

The regeneration features of DTC-PGMA@SiO ${ }_{2}$ adsorbent for repeated use were investigated. The $\mathrm{pH}$ factor has obviously been taken into account, due to which, the $\mathrm{pH}$ has proven to be a remarkable influencing factor in the binding interactions between DTC groups and metallic ions. Because of the significant chelating ability of EDTA, it was also used to further improve the metallic ions' desorption from the adsorbent. After four reuse 
cycles, the removal efficiencies for $\mathrm{Cu}^{2+}, \mathrm{Pb}^{2+}$ and $\mathrm{Cd}^{2+}$ were $85.7 \%, 84.3 \%$ and $63.5 \%$ respectively, which decreased slightly compared with the corresponding values for the first cycle (see Fig. S9†). These results demonstrated that an effective regeneration of DTC-PGMA@SiO ${ }_{2}$ can be achieved, which makes it sustainable and economically valuable adsorbent for wastewater treatment.

\section{Conclusions}

In summary, a novel nanostructured DTC-PGMA@SiO adsor- $^{-}$ bent material containing well-defined core-brush structure was synthesized via SI-ATRP and subsequent DTC group functionalization. The high-density (grafting ratio is $62.4 \%$ ) and narrowdistribution polymer brushes, which contain abundant DTC groups ( $6.52 \mathrm{mmol} \mathrm{g}^{-1}$ ), were identified by combining multiple techniques. The nanostructured DTC-PGMA@SiO ${ }_{2}$ adsorbent exhibits remarkable adsorption performance for $\mathrm{d}^{9}$ and $\mathrm{d}^{10}$ type heavy metal ions, including considerable adsorption capacities (the adsorption capacities for $\mathrm{Cu}^{2+}, \mathrm{Pb}^{2+}$ and $\mathrm{Cd}^{2+}$ were found to be $3.60,1.96$ and $1.47 \mathrm{mmol} \mathrm{g}^{-1}$, respectively) and rapid adsorption equilibriums (within $30 \mathrm{~min}$ ), which were attributed to the sea anemone-like core-brush structure, large specific surface area and high affinity between DTC groups and metallic ions. The adsorption process can be well-described by the pseudo-second-order and Langmuir models, indicating a spontaneous monolayer chemisorption occurring on the adsorbent surface. The adsorption mechanism between metal ions and DTC-PGMA@SiO $\mathrm{S}_{2}$ adsorbent relies on synergistic combination of electrostatic interaction and coordination interaction between heavy metal ions and DTC groups. Additionally, the effective regeneration was achieved. These results highlight the promising potential of DTC-PGMA@SiO ${ }_{2}$ for treating water bodies contaminated by heavy metal ions.

\section{Acknowledgements}

The authors are grateful for financial support from the National Natural Science Foundation of China (Grant No. 21374055) and the Major Research of Science and Technology, China (Grant No. 2016ZX05025-003).

\section{Notes and references}

1 C. J. Vörösmarty, P. B. McIntyre, M. O. Gessner, D. Dudgeon, A. Prusevich, P. Green, S. Glidden, S. E. Bunn, C. A. Sullivan, C. R. Liermann and P. M. Davies, Nature, 2010, 467, 555-561.

2 Q. Peng, J. Guo, Q. Zhang, J. Xiang, B. Liu, A. Zhou, R. Liu and Y. Tian, J. Am. Chem. Soc., 2014, 136, 4113-4116.

3 W.-H. Leung, P.-K. So, W.-T. Wong, W.-H. Lo and P.-H. Chan, RSC Adv., 2016, 6, 106837-106846.

4 A. Eichler, L. Tobler, S. Eyrikh, N. Malygina, T. Papina and M. Schwikowski, Environ. Sci. Technol., 2014, 48, 2635-2642.

5 R. M. Izatt, S. R. Izatt, R. L. Bruening, N. E. Izatt and B. A. Moyer, Chem. Soc. Rev., 2014, 43, 2451-2475.

6 Z. Li, J. Chen, H. Guo, X. Fan, Z. Wen, M. H. Yeh, C. Yu, X. Cao and Z. L. Wang, Adv. Mater., 2016, 28, 2983-2991.
7 J. Tang, B. Mu, M. Zheng and A. Wang, ACS Sustainable Chem. Eng., 2015, 3, 1125-1135.

8 J. Yang, K. Yu and C. Liu, J. Hazard. Mater., 2017, 321, 73-80.

9 B. L. Rivas, E. D. Pereira, M. Palencia and J. Sánchez, Prog. Polym. Sci., 2011, 36, 294-322.

10 S. A. El-Safty, S. Abdellatef, M. Ismael and A. Shahat, Adv. Healthcare Mater., 2013, 2, 854-862.

11 F. Liu, C. Shan, X. Zhang, Y. Zhang, W. Zhang and B. Pan, J. Hazard. Mater., 2017, 321, 290-298.

12 D. Nagai, M. Yoshida, T. Kishi, H. Morinaga, Y. Hara, M. Mori, S. Kawakami and K. Inoue, Chem. Commun., 2013, 49, 6852-6854.

13 M. M. Nasef and O. Güven, Prog. Polym. Sci., 2012, 37, 15971656.

14 J. Zhou, V. W.-C. Chang and A. G. Fane, Energy Environ. Sci., 2011, 4, 2267-2278.

15 D. Godinho, D. Dias, M. Bernardo, N. Lapa, I. Fonseca, H. Lopes and F. Pinto, J. Hazard. Mater., 2017, 321, 173-182.

16 M. Liu, B. Zhang, H. Wang, F. Zhao, Y. Chen and Q. Sun, RSC $A d v .$, 2016, 6, 67057-67071.

17 J. Zhao, Z. Li, J. Wang, Q. Li and X. Wang, J. Mater. Chem. A, 2015, 3, 15124-15132.

18 A. Farrukh, A. Akram, A. Ghaffar, S. Hanif, A. Hamid, H. Duran and B. Yameen, ACS Appl. Mater. Interfaces, 2013, 5, 3784-3793.

19 Z. Sekhavat Pour and M. Ghaemy, RSC Adv., 2015, 5, 6410664118.

20 C. Chen, R. Wang, L. Guo, N. Fu, H. Dong and Y. Yuan, Org. Lett. , 2011, 13, 1162-1165.

21 B. Ochiai, T. Ogihara, M. Mashiko and T. Endo, J. Am. Chem. Soc., 2009, 131, 1636-1637.

22 Y. Ge, D. Xiao, Z. Li and X. Cui, J. Mater. Chem. A, 2014, 2, 2136-2145.

23 C. Gai, Y. Guo, N. Peng, T. Liu and Z. Liu, $R S C A d v .$, 2016, 6, 53713-53722.

24 F. Di Natale, A. Erto, A. Lancia and D. Musmarra, J. Hazard. Mater., 2015, 281, 47-55.

25 D. S. Tavares, C. B. Lopes, A. L. Daniel-da-Silva, A. C. Duarte, T. Trindade and E. Pereira, Chem. Eng. J., 2014, 254, 559-570. 26 P. Z. Ray and H. J. Shipley, RSC Adv., 2015, 5, 29885-29907. 27 M. M. Khin, A. S. Nair, V. J. Babu, R. Murugan and S. Ramakrishna, Energy Environ. Sci., 2012, 5, 8075.

28 J. Zhang and Y. Chen, RSC Adv., 2016, 6, 69370-69380.

29 H. Gao, Y. Sun, J. Zhou, R. Xu and H. Duan, ACS Appl. Mater. Interfaces, 2013, 5, 425-432.

30 M. Y. Nassar and S. Abdallah, RSC Adv., 2016, 6, 84050-84067. 31 F. Perreault, A. Fonseca de Faria and M. Elimelech, Chem. Soc. Rev., 2015, 44, 5861-5896.

32 J. J. Alcaraz-Espinoza, A. E. Chávez-Guajardo, J. C. MedinaLlamas, C. A. Andrade and C. P. de Melo, ACS Appl. Mater. Interfaces, 2015, 7, 7231-7240.

33 N. Zhang, G. L. Zang, C. Shi, H. Q. Yu and G. P. Sheng, J. Hazard. Mater., 2016, 316, 11-18.

34 D. Yang, X. Pang, Y. He, Y. Wang, G. Chen, W. Wang and Z. Lin, Angew. Chem., Int. Ed., 2015, 54, 12091-12096.

35 D. Zheng, X. Pang, M. Wang, Y. He, C. Lin and Z. Lin, Chem. Mater., 2015, 27, 5271-5278. 
36 X.-Q. Liu, Y.-L. Li, Y.-W. Lin, S. Yang, X.-F. Guo, Y. Li, J. Yang and E.-Q. Chen, Macromolecules, 2013, 46, 8479-8487.

37 D. Kundu, C. Hazra, A. Chatterjee, A. Chaudhari, S. Mishra, A. Kharat and K. Kharat, RSC Adv., 2016, 6, 80438-80454.

38 W. Hu, Y. Liu, T. Chen, Y. Liu and C. M. Li, Adv. Mater., 2015, 27, 181-185.

39 W. Mai, B. Sun, L. Chen, F. Xu, H. Liu, Y. Liang, R. Fu, D. Wu and K. Matyjaszewski, J. Am. Chem. Soc., 2015, 137, 1325613259.

40 A. F. Hirschbiel, S. Geyer, B. Yameen, A. Welle, P. Nikolov, S. Giselbrecht, S. Scholpp, G. Delaittre and C. BarnerKowollik, Adv. Mater., 2015, 27, 2621-2626.

41 Y. Yue, R. T. Mayes, J. Kim, P. F. Fulvio, X. G. Sun, C. Tsouris, J. Chen, S. Brown and S. Dai, Angew. Chem., Int. Ed., 2013, 52, 13458-13462.

42 S. Yuan, J. Gu, Y. Zheng, W. Jiang, B. Liang and S. O. Pehkonen, J. Mater. Chem. A, 2015, 3, 4620-4636.

43 Y. Chen, M. He, C. Wang and Y. Wei, J. Mater. Chem. A, 2014, 2, 10444.

44 M. Cvek, M. Mrlik, M. Ilcikova, T. Plachy, M. Sedlacik, J. Mosnacek and V. Pavlinek, J. Mater. Chem. C, 2015, 3, 4646-4656.

45 J. Pan, J. Zeng, Q. Cao, H. Gao, Y. Gen, Y. Peng, X. Dai and Y. Yan, Chem. Eng. J., 2016, 284, 1361-1372.

46 B. Ernould, M. Devos, J.-P. Bourgeois, J. Rolland, A. Vlad and J.-F. Gohy, J. Mater. Chem. A, 2015, 3, 8832-8839.

47 J. M. Bak and H.-I. Lee, Polymer, 2012, 53, 4955-4960.

48 J. Luo, F. Zhao, X. Fei, X. Liu and J. Liu, Chem. Eng. J., 2016, 293, 171-181.

49 S. G. J. Emmerling, L. B. N. Langer, S. A. Pihan, P. Lellig and J. S. Gutmann, Macromolecules, 2010, 43, 5033-5042.

50 S. Banerjee, T. K. Paira, A. Kotal and T. K. Mandal, Adv. Funct. Mater., 2012, 22, 4751-4762.

51 G. Yin, D. Zhao, L. Zhang, Y. Ren, S. Ji, H. Tang, Z. Zhou and Q. Li, Chem. Eng. J., 2016, 302, 1-11.

52 N. R. Ko, G. Sabbatier, A. Cunningham, G. Laroche and J. K. Oh, Macromol. Rapid Commun., 2014, 35, 447-453.
53 X. Wang, J. Cai, Y. Zhang, L. Li, L. Jiang and C. Wang, J. Mater. Chem. A, 2015, 3, 11796-11800.

54 A. S. Krishna Kumar, S.-J. Jiang and W.-L. Tseng, J. Mater. Chem. A, 2015, 3, 7044-7057.

55 E. R. Nightingale, J. Phys. Chem., 1959, 63, 1381-1387.

56 L. Wang, C. Cheng, S. Tapas, J. Lei, M. Matsuoka, J. Zhang and F. Zhang, J. Mater. Chem. A, 2015, 3, 13357-13364.

57 X. Jing, F. Liu, X. Yang, P. Ling, L. Li, C. Long and A. Li, J. Hazard. Mater., 2009, 167, 589-596.

58 X. Wang, S. Jing, X. Qiu, S. Zhao, Y. Liu and Y. Tan, Chem. Eng. J., 2016, 304, 493-502.

59 M. L. Rahman, S. M. Sarkar, M. M. Yusoff and M. H. Abdullah, RSC Adv., 2016, 6, 745-757.

60 J. Ma, Y. Shen, C. Shen, Y. Wen and W. Liu, Chem. Eng. J., 2014, 248, 98-106.

61 W. Liu, D. Wei, J. Mi, Y. Shen, B. Cui and C. Han, Chem. Eng. J., 2015, 277, 312-317.

62 P. Tan, J. Sun, Y. Hu, Z. Fang, Q. Bi, Y. Chen and J. Cheng, J. Hazard. Mater., 2015, 297, 251-260.

63 P. Tan, J. Wen, Y. Hu and X. Tan, RSC Adv., 2016, 6, 7964179650.

64 I. E. M. Carpio, J. D. Mangadlao, H. N. Nguyen, R. C. Advincula and D. F. Rodrigues, Carbon, 2014, 77, 289-301.

65 Q. Zhu and Z. Li, Chem. Eng. J., 2015, 281, 69-80.

66 D. Liu, Z. Li, W. Li, Z. Zhong, J. Xu, J. Ren and Z. Ma, Ind. Eng. Chem. Res., 2013, 52, 11036-11044.

67 H. Chen, X. Wang, J. Li and X. Wang, J. Mater. Chem. A, 2015, 3, 6073-6081.

68 R. Cao Jr, A. Díaz, R. Cao, A. Otero, R. Cea, M. C. RodríguezArgüelles and C. Serra, J. Am. Chem. Soc., 2007, 129, 69276930.

69 K. Zargoosh, H. Abedini, A. Abdolmaleki and M. R. Molavian, Ind. Eng. Chem. Res., 2013, 52, 14944-14954.

70 D. Gao, F. Scholz, H. G. Nothofer, W. E. Ford, U. Scherf, J. M. Wessels, A. Yasuda and F. von Wrochem, J. Am. Chem. Soc., 2011, 133, 5921-5930. 